$\xi_{p}=$

\title{
Effects of tributyltin chloride (TBTCI) antifouling biocide on adult males and females of brine shrimp (Artemia salina)
}

\author{
Najla Mohamed Abu Shaala ${ }^{1}$, Syaizwan Zahmir Zulkifli ${ }^{1}{ }^{*}$, Ahmad Ismail ${ }^{1}$, Mohammed Noor Amal Azmai ${ }^{1}$, \\ Ferdaus Mohamat-Yusuff ${ }^{2}$, Hishamuddin Omar ${ }^{1}$ \\ ${ }^{1}$ Department of Biology, Faculty of Science, Universiti Putra Malaysia, 43400 UPM Serdang, Selangor, Malaysia \\ ${ }^{2}$ Department of Environmental Sciences, Faculty of Environmental Studies, Universiti Putra Malaysia, \\ 43400 UPM Serdang, Selangor, Malaysia \\ *Corresponding author E-mail: syaizwan@upm.edu.my
}

\begin{abstract}
Elevation of tributyltin (TBT) concentration in marine environment could affect targeted and non-targeted organisms at any lifestage. The present study aimed to determine median lethal concentration ( $\left.\mathrm{LC}_{50}\right)$ and morphological effects of tributyltin chloride (TBTCl) on adult males and females of brine shrimp (Artemia salina). The adult males and females of A. salina were exposed to different concentration of TBTCl. Morphological condition of every A. salina individuals were observed under a microscope. Results showed the LC 50 of TBTCl among adult males of $A$. salina was $146.99 \mathrm{ng} . \mathrm{L}^{-1}$ and for the females was $94.72 \mathrm{ng} . \mathrm{L}^{-1}$, respectively. The LC50 of TBTCl was significantly different among different sexes. There was also a significant difference in some morphological characters of males and females exposed to different TBTCl concentrations. These morphological changes include their total length, head width, abdominal width, and tail width after the $24 \mathrm{hr}$ exposure to TBTCl. These results suggested that suspensions of the TBTCl were toxic to Artemia, most likely due to the formation of benign TBTCl aggregates in water. However, the mortality increased with extended exposure to 24hr. Highest mortality occurred at $200 \mathrm{ng} . \mathrm{L}^{-1} \mathrm{TBTCl} ; 43.33 \%$ for male and $90 \%$ for female $\left(\mathrm{LC}_{50}<150 \mathrm{ng} . \mathrm{L}^{-1}\right)$ for both. Depended on this the female was more sensitive for TBTCl toxicity test when compared to male. These effects were attributed to changes in morphological characteristics of the body A. salina.
\end{abstract}

Keywords: Organotin; Antifouling Biocide; Artemia salina; Toxicity; Morphology.

\section{Introduction}

Fouling is a major problem for the shipping industry because friction between the hull and seawater will be increased, which in combination with the increased weight of the fouling organisms can lead to a considerable increase in fuel consumption (Panagoula et al. 2002, Mohamat-Yusuff et al. 2010). Fouling is also implicated in the spread of invasive species across the world's oceans because they are regarded as a threat to native aquatic fauna, causing demise or the native species to vanish by competitive exclusion, introduction of diseases, or predation (Bartley \& Minchin 1996).

Tributyltin (TBT) based antifouling paints was proven to be more efficient to prevent formation of fouling colonies (Abubakar et al. 2016). These paints were distributed under various product names, including Alumacoat, Bioclean, TinSan and Fungitrol (Fergusson 2015). There are also many organic compounds have been introduced in antifouling paint formulations, as booster biocides (Ismail et al. 2004, Cima et al. 2008). These antifoulants have been introduced in paint formulations to increase their performance against a wide spectrum of fouling organisms (Bustos-Obregon \& Vargas 2010).

However, TBT was proven as highly toxic pollutants, mainly introduced to the environment as a marine antifouling agent (AlRashdi 2011, Mohamat-Yusuff et al. 2014). TBT have been widely used in antifouling paints applied to boats and aquaculture nets in order to provide growth inhibition of algae, crustaceans, shell fish, etc. Lethal effects and sublethal toxic effects of TBT on juvenile growth, larval development and reproduction of molluscs are caused even by amounts in the range of ng/L or less (Bryan \& Gibbs 1991, Alzieu 1998, Shaala et al. 2015a). Therefore, the use of TBT as an antifouling paint for boats less than $25 \mathrm{~m}$ in length and for aquaculture nets was restricted in most developed countries in the late 1980s and in Japan in 1990 (Ohji et al. 2002, Champeau \& Narbonne 2006). However, in the 1980s, when several impacts of TBT paints to aquatic organisms started to be described (e.g., abnormal growth, poor and reproductive failure in cultivated oysters Crassostrea gigas, imposex in female dogwhelks and tropical neogastropods etc. (Alzieu 1998, Mohamat-Yusuff et al. 2011, 2014). The TBT is consist of three alkyl groups attached to the tin atom, containing the element tin (Sn) which belongs to Group IV of the periodic table.

The brine shrimp Artemia is zooplankton, like copepods and daphnia, which are used as live food in the aquarium trade and for marine finfish and crustacean larval culture (Sahandi et al. 2012, Hassanatabar et al. 2013, Shaala et al. 2015b). This genus is characterized by its adaptability to hypersaline environments. A. salina is an example of a bisexual species. For taxonomic purposes, criteria such as morphology of adults, specific numbers of chromosomes, genetic distance and crossbreeding experiments have been used extensively (Abreu-Grobois 1987). A. salina (brine shrimp) is zooplankton that is used to feed larval fish in cultures like copepods and daphnids (Sorgeloos et al. 1980, Roozbehfar et al. 2012). They play an important role in the energy flow of the food chain in the 
marine environment. Among scientists, they are used as a laboratory bioassay organism to develop standard toxicology assays (Nunes et al. 2006, Kanwar 2007). Artemia is hypo hyper-osmotic regulators that are able to maintain hemolymph ion concentrations within narrow limits over an external salinity range from $0.26 \%$ $\mathrm{NaCl}$ to supersaturated brines. With this capability, Artemia appears to be suitable model species to investigate the fate and ecotoxicity of nanomaterials in marine ecosystems through laboratory experiments. They have some important advantages including constant commercial availability during the year a round, cost efficiency, ease to culture, short life-cycle, no feeding required during the assay and great offspring production (Nunes et al. 2006). These advantages have led to a wide range of Artemia-based bioassays. The determination of the $\mathrm{LC}_{50}$ of the adults (male and female), after hatchability the cysts and culture to get adults age specimens, and the disruptions on an enzyme property (Varó et al. 2002) are only some of the Artemia end-points that have already been examined as evidence of toxicity (Kokkali et al. 2011). The high tolerance of Artemia adults to metals, coupled with the need for an inexpensive system to study pollution of marine environments, has prompted us to consider adult stages of Artemia to be used as testing organisms for the assessment of TBTCl pollution. In this study, we conducted exposure studies on Artemia adults, male and female in aqueous suspensions of TBTCl to determine median lethal concentration $\left(\mathrm{LC}_{50}\right)$ and the effects of TBTCl on morphological characteristics of male and female brine shrimps (A. salina).

\section{Materials and methods}

A standard artificial seawater of $(35 \pm 1 \%$ ) was used for the culture to Artemia as well as for the toxicity test. The sea artificial salt mixtures (Instant Ocean ${ }^{\circledR}$; Aquarium Systems, Sarrebourg, France) were prepared. Synthetic sea salt dissolved in distilled water. After aeration and stabilization for 24 hour, the sea water was having a $\mathrm{pH}$ of $8.0 \pm 0.5$ and the low oxygen content should be at least $90 \%$ saturation. If necessary the $\mathrm{pH}$ should be adjusted with concentrated hydrochloric acid or sodium hydroxide. The artificial sea water was filtered through a $1 \mu \mathrm{m}$ filter using a vacuum (Nunes et al. 2006). The TBTCl $\left(\mathrm{C}_{12} \mathrm{H}_{27} \mathrm{ClSn}\right)$ is a product of the Sigma-Aldrich, USA (purity 96\%). The preparation of TBTCl stock 1 ppm.L. $\mathrm{L}^{-1}$ was dissolved in prepared sea water (salinity $35 \pm 1 \%$ ). Further dilution of TBTCl was made using synthetic seawater. The stock solutions of the toxicant were stored for no more than 48 hour. A range finding test for TBTCl toxicants was conducted. A serial concentrations of TBTCl dilutions used were $25 \mathrm{ng} . \mathrm{L}^{-1}, 50 \mathrm{ng} . \mathrm{L}^{-1}, 150 \mathrm{ng} . \mathrm{L}^{-1}, 200$ ng.. $\mathrm{L}^{-1}, 250$ ng. $\mathrm{L}^{-1}$, and 300 ng.. $\mathrm{L}^{-1}$.

Artemia salina (Linnaeus, 1758) cysts are, originated from Great Salt Lake, Utah. For hatching we used approximately 0.5 of cysts from A. salina was culture in a $1 \mathrm{~L}$ aquarium at $35 \%$ salinity at 28 $\pm 1{ }^{\circ} \mathrm{C}$ for 24 hour under standardized hatching conditions. Artemia instar I nauplii were inoculated into $1 \mathrm{~L}$ conical glass tubes at $35 \%$ salinity, water $\mathrm{pH}(7.0-8.5)$ and tubes were provided with aeration to ensure continuous supply of oxygen in the cultures. The experimentation was carried out using white neon light illumination with photoperiod $12 / 12$. All the nauplii were kept at a temperature of $28 \pm 1{ }^{\circ} \mathrm{C}$. Uneaten food and wastes from Artemia were daily removed by siphoning before feeding, while aeration was briefly interrupted (Toi et al. 2013)

A marine algae Tetraselmis sp. used for feeding A. salina (Toi et al. 2013). The microalgae concentrate contains intact cells that are non-viable. The latter was verified by the absence of $\mathrm{pH}$ change over a period of 6 hours with continuous illumination at an algae concentrate density of $1 \mathrm{~g} . \mathrm{L}^{-1}$.

The toxicity test was carried out in tube $50 \mathrm{ml}$. The five individuals of male and female were transferred with a Pasteur pipette into each tube. The volume of seawater carried over with the Artemia was minimal. After that, the toxicant dilutions were conducted. Each toxicant dilution was added to the tube. The tubes were filled with $50 \mathrm{ml}$ of the respective concentrations of the toxin, and an incubated at a temperature of $25 \pm 1{ }^{\circ} \mathrm{C}$ for 24 hours. Then, the mortality of
Artemia was transferred and recorded in Petri dish was placed on the stage of the dissection microscope and estimate. After that, the mortality percentage was calculated from the total number of organisms in the test for each concentration. And the survivors were used to study the effect of toxicant on their morphological abnormalities. The morphological abnormalities of exposed A. salina in each toxicant were observed under magnification (10x) using binocular microscopy attached to a camera with an aid of software (Dino-Lite Edge Digital Microscope - AM4515ZT). Statistical analyses were performed using XLStat-Pro (Version 2014.5.03) to determine the $\mathrm{LC}_{50}$ and SPSS (version 22) test for significant differences between the results of the individual treatments. Differences between doses (treatments) were tested for significance using a one-way analysis of variance (ANOVA), with an $\alpha$ of 0.05 . The correlation was used to examine the correlation between concentrations of TBTCl and total length, head, abdomen and tail width. A probability value of $\mathrm{p}<0.05$ was considered as statistically significant.

\section{Results and discussion}

Table 1: Mortality Percentage of Adult Females and Males of A. salina Exposed To Different Concentration of TBTCl (ng. $\left.\mathrm{L}^{-1}\right)$ For 24 Hours

\begin{tabular}{ccc}
\hline Concentration $\left(\mathrm{ng} / \mathrm{L}^{-1}\right)$ & \multicolumn{2}{c}{ Mortality $(\%)$} \\
& Male & Female \\
\hline 0 & 0.00 & 0 \\
25 & 0.00 & 25 \\
50 & 0.00 & 50 \\
100 & 13.33 & 100 \\
150 & 36.67 & 150 \\
200 & 43.33 & 90 \\
250 & 100 & 100 \\
\hline
\end{tabular}

The mortality results showed that the toxicity range from $0 \%$ to $100 \%$ mortality was between $25 \mathrm{ng} . \mathrm{L}^{-1}$, and $300 \mathrm{ng} . \mathrm{L}^{-1}$, for TBTCl. Based on these data the definitive test was designed and the concentration used for TBTCl toxicants are shown in Table 1. The respective 24 hours mortality values of $A$. salina for TBTCl are shown in Figure 1 which indicates the relationship between mortality rates and increasing concentration of $\mathrm{TBTCl}, \quad$ respectively. The $\mathrm{LC}_{50}$ values were determined by the XLStat-Pro software. In this case of TBTCl concentrations were 25 ng.L $\mathrm{L}^{-1}, 50$ ng.L $\mathrm{L}^{-1}, 100 \mathrm{ng.L}$ 1, 150 ng.L $\mathrm{L}^{-1}, 200$ ng. $\mathrm{L}^{-1}, 250 \mathrm{ng} . \mathrm{L}^{-1}$ and $300 \mathrm{ng} . \mathrm{L}^{-1}$, respectively. The minimum and upper limits of $\mathrm{LC}_{50}$ values of TBTCl were 25 ng. $\mathrm{L}^{-1}$ and 300 ng. $\mathrm{L}^{-1}, \mathrm{LC}_{50}$ values for TBTCl determined in the present study female is $94.72 \mathrm{ng} . \mathrm{L}^{-1}$ and the male is $146.99 \mathrm{ng} . \mathrm{L}^{-1}$ (Figure 1). The toxicity of TBTCl was tested on adults of brine shrimp A. salina and their morphological characteristics change of total length, head width, abdominal width, tail width were observed during the 24 hours period.

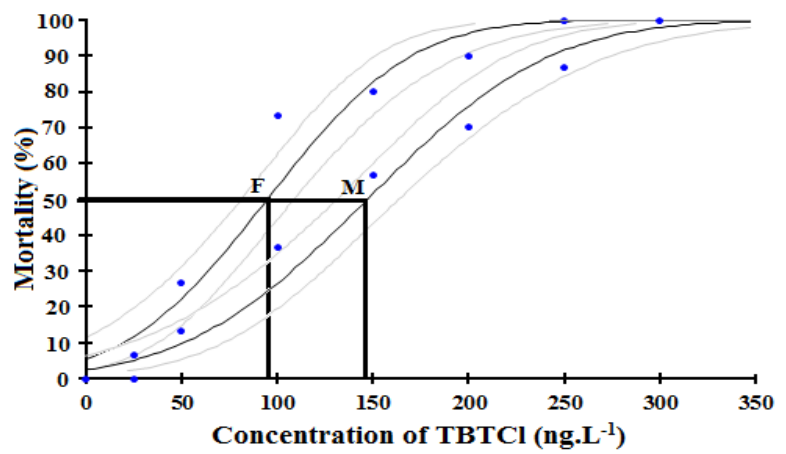

Fig. 1: Relationship between Concentrations of TBTCl and Mortality (\%) Shows the in the Male $\mathrm{LC}_{50}$ Is (146.99 ng.L $\left.\mathrm{L}^{-1}\right)$ and in Female $\mathrm{LC}_{50}$ Is $(94.72$ ng. $\left.\mathrm{L}^{-1}\right)$. 
Table 2: Measurement of Total Length (TL), Head Width (HW), Abdomen Width (AW) and Tail Width (TW) of Female and Male Adult A. salina after 24 Hours Exposure to Different TBTCl Concentrations.

\begin{tabular}{|c|c|c|c|c|c|c|}
\hline Gender & Concentration & No. of samples & Total length $(\mu \mathrm{m})$ & Head width $(\mu \mathrm{m})$ & Abdomen width $(\mu \mathrm{m})$ & Tail width $(\mu \mathrm{m})$ \\
\hline \multirow{7}{*}{ Female } & $\mathrm{NC}$ & 30 & 8360.95 & 992.280 & 654.28 & 400.01 \\
\hline & 25 & 30 & 6117.33 & 786.16 & 607.31 & 298.38 \\
\hline & 50 & 30 & 6456.34 & 1081.07 & 619.44 & 423.19 \\
\hline & 100 & 30 & 2476.89 & 293.10 & 178.49 & 101.02 \\
\hline & 150 & 30 & 1924.39 & 182.15 & 132.69 & 83.63 \\
\hline & 200 & 30 & 981.49 & 95.51 & 74.19 & 39.17 \\
\hline & Mean & 180 & 4386.23 & 571.71 & 377.74 & 224.23 \\
\hline \multirow{8}{*}{ Male } & $\mathrm{NC}$ & 30 & 8012.82 & 789.00 & 644.12 & 290.24 \\
\hline & 25 & 30 & 6858.04 & 887.89 & 680.17 & 360.42 \\
\hline & 50 & 30 & 6444.47 & 849.70 & 696.43 & 326.14 \\
\hline & 100 & 30 & 3538.72 & 435.09 & 320.93 & 151.74 \\
\hline & 150 & 30 & 2462.19 & 304.43 & 229.12 & 96.73 \\
\hline & 200 & 30 & 1875.68 & 265.03 & 252.77 & 123.65 \\
\hline & 250 & 30 & 803.71 & 103.63 & 95.80 & 51.05 \\
\hline & Mean & 210 & 4285.09 & 519.25 & 417.049 & 199.99 \\
\hline
\end{tabular}

Remark: NC = negative control
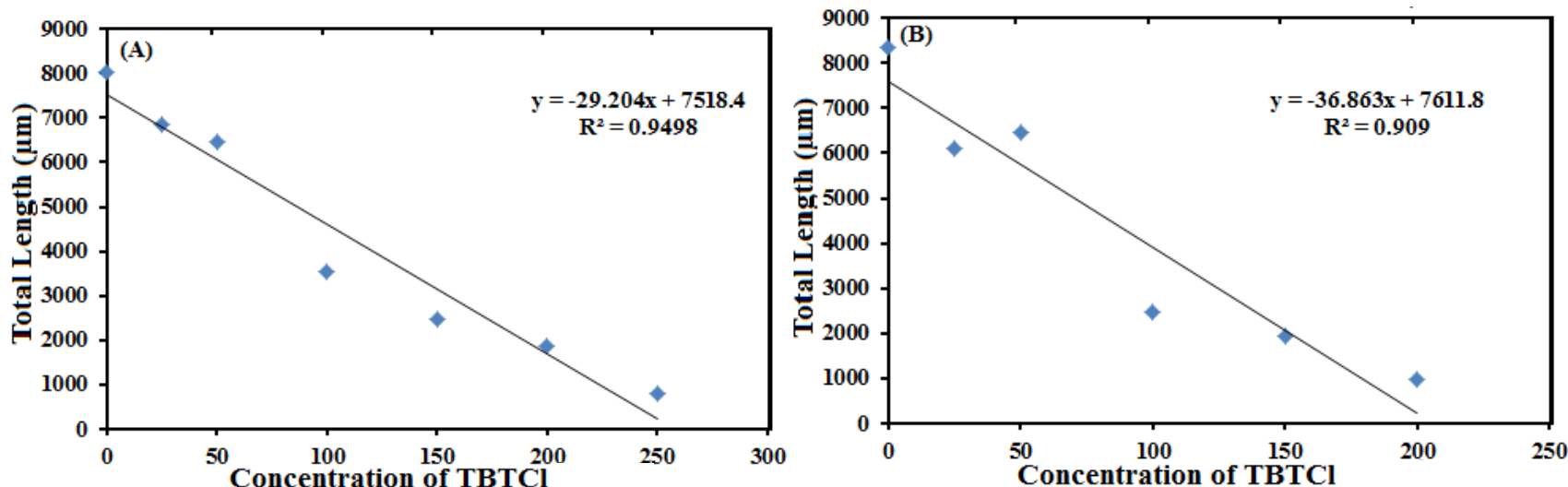

Fig. 2: Morphological Condition of A. salina Exposed the Relationship between Different Concentration of TBTCl (ng.L $\left.{ }^{-1}\right)$ and Total Length ( $\mu$ m) $[(\mathrm{A})$ Male, (B) Female].
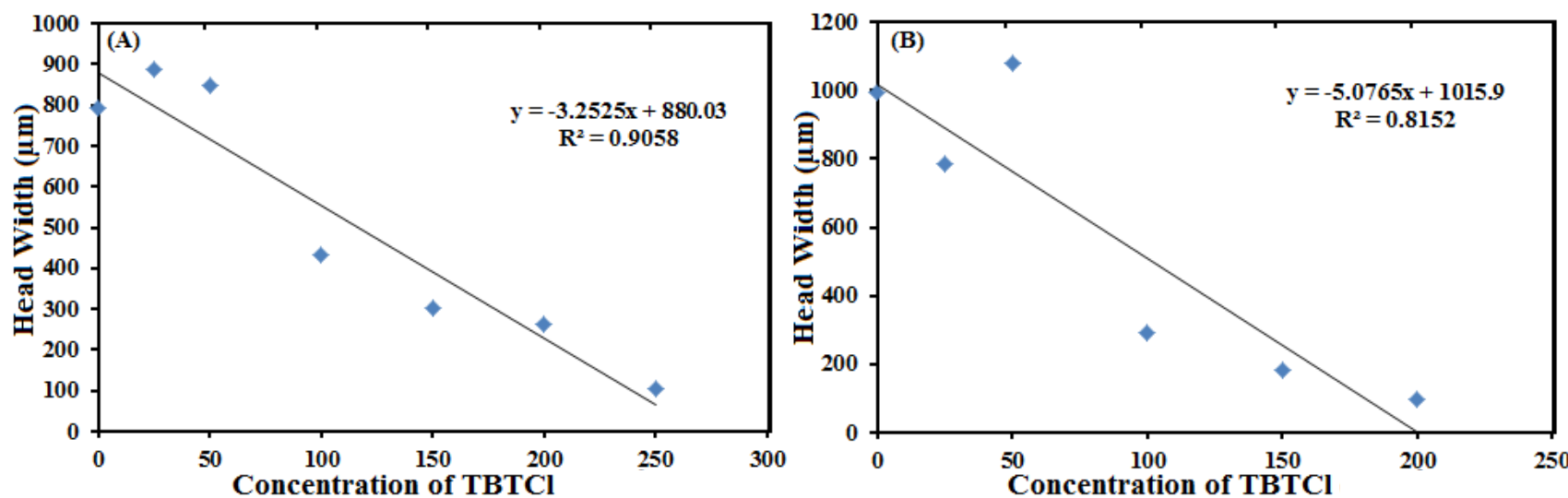

Fig. 3: Morphological Condition of $A$. salina Exposed the Relationship between Different Concentration of TBTCl (ng.L $\left.{ }^{-1}\right)$ and Head Width ( $\mu$ m) $[(\mathrm{A})$ Male, (B) Female].

The toxicity concentration varied obviously at different concentration in A. salina adults and the variation was due to increase in concentration of TBTCl, thereby increase the effect on A. salina. The one-way ANOVA indicated a significant difference at $\mathrm{p}<0.01$ between the average mean of morphological characteristics due to the increase concentration of TBTCl resulted to decrease in general morphological characteristics of $A$. salina adults (Table 2). The minimum and maximum toxicity concentration shows a variation in the total length (TL), head width (HW), abdomen width (AW) and tail width (TW) at a range of $0.00-9886.74$ ng. $\mathrm{L}^{-1}, 0.00$ - 1235.51 ng.L ${ }^{-1}, 0.00-1316.65$ ng. $L^{-1}$, and $0.00-603.75$ ng.L ${ }^{-1}$ respectively in male and female were $0.00-11369.81 \mathrm{ng} . \mathrm{L}^{-1}, 0.00$ -9274.07 ng.L ${ }^{-1}, 0.00-1213.62$ ng.L ${ }^{-1}$, and $0.00-801.05$ ng.L ${ }^{-1}$, respectively (Table 3 ). These results demonstrated that $\mathrm{TBTCl}$ is responsible for the change in total length and width of body of $A$. salina after 24 hours exposure. Generally, TL, HW, AW and TW decreased when TBTCl concentration is increased (Figure 2 until
Figure 5) in males and in females. Significant differences in morphological were observed in all survivors $A$. salina males and females exposed to all toxicants concentration of TBTCl (Figure $6)$.

Based on these findings the A. salina female is more sensitive to TBTCl toxicity test when compared with male. The toxicity of TBTCl was tested against $A$. salina and the morphological changes in the male and female of brine shrimp, which undergo certain changes in morphological characteristics, as well as total 

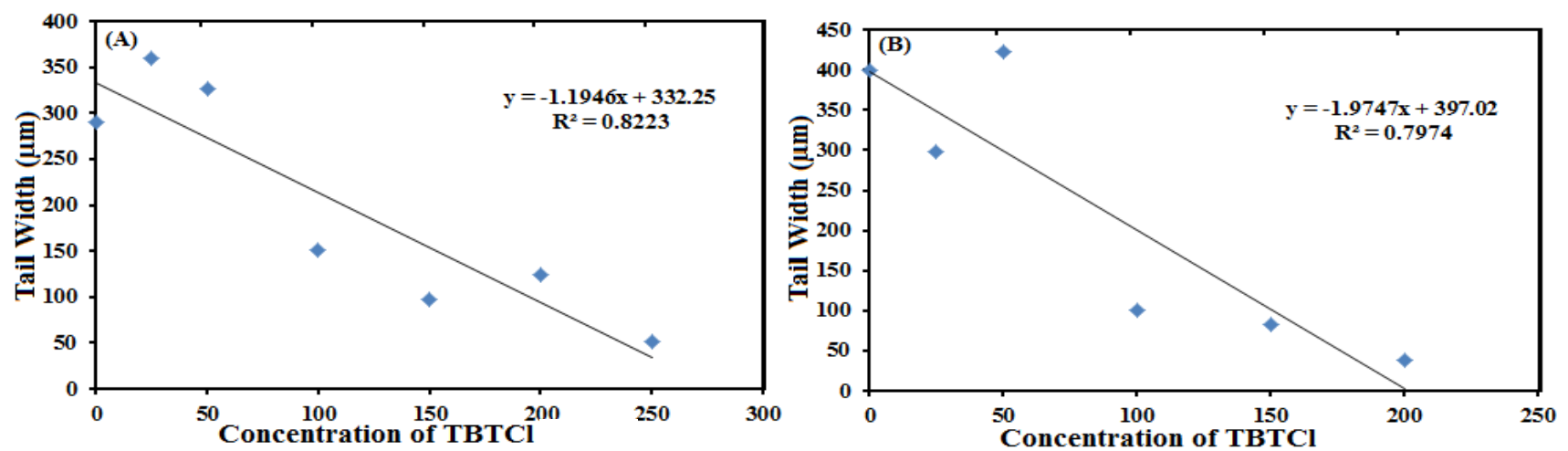

Fig. 5: Morphological Condition of A. salina Exposed the Relationship between Different Concentration of TBTCl (ng.L ${ }^{-1}$ ) and Tail Width ( $\mu$ m) $[($ A) Male, (B) Female].

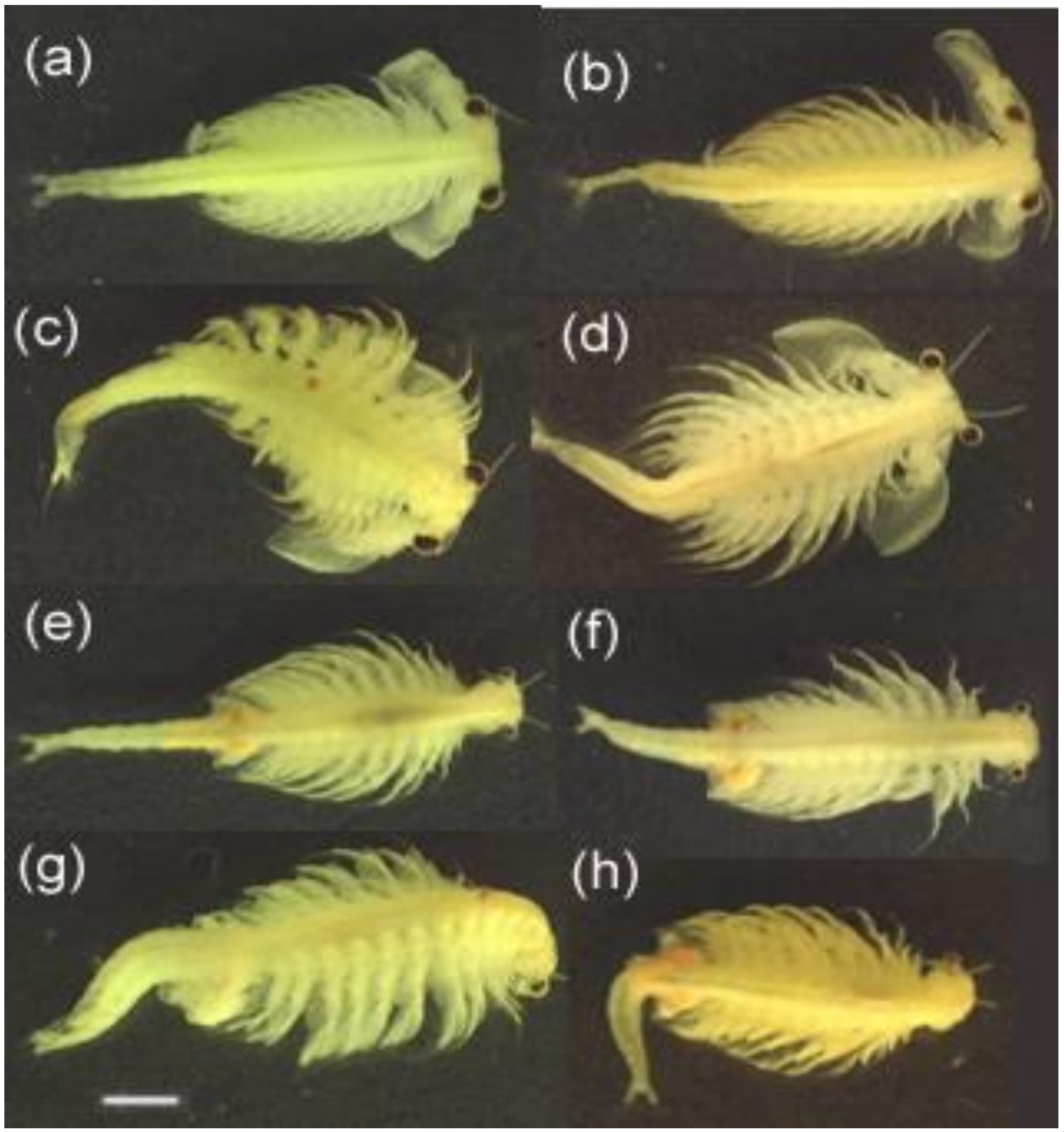

Fig. 6: Morphological Conditions of A. salina Males and Females Exposed To Different TBTCl Concentrations. [(A) Negative Control Male (B) 50 ng.L ${ }^{-1}$ (C) 200 ng.L $\mathrm{L}^{-1}$ (D) $\left.300 \mathrm{ng} . \mathrm{L}^{-1}\right]$ and [(E) Negative Control Female (F) 25 ng.L $\mathrm{L}^{-1}$ (G) 50 ng.L $\mathrm{L}^{-1}$ (H) 300 ng.L $\left.{ }^{-1}\right]$ Bar: $1000 \mu \mathrm{m}$. 
length, head width, abdominal width, tail width during the 24 hours period. The one-way ANOVA employed indicated a substantial difference at $\mathrm{p}<0.01$ between the average means of total length, head width, abdomen width and tail width, with the different toxic concentration. This indicated that the changes are decrease when increasing the morphological TBTCl.

There is not enough study about the effects TBTCl on the male and female, so we compare our results with other results from the same classification crustacean. There was a study conducted by Verslycke et al. (2003) which found the effects of TBTCl on the phase I and II testosterone metabolism of Neomysis integer were evaluated. The TBTCl was highly toxic to N. integer (96-h median lethal concentration $\mathrm{LC}_{50}$ of $164 \mathrm{ng} . \mathrm{L}^{-1}$. This study revealed TBTCl to be toxic and proven as an environmentally toxic substance. Literature regarding toxicity testing with the brine shrimp species A. salina demonstrates the female high sensitivity more than male, at adult levels that are likely to occur in the environment (Verslycke et al., 2003). The acute LC 50 for adult $A$. salina of 94.72 ng. $\mathrm{L}^{-1}$ in female and 146.99 ng. $\mathrm{L}^{-1}$ in male of TBTCl found in this study is lower than that reported by Verslycke et al. (2003) for $N$. integer (164 ng. $\mathrm{L}^{-1}$ of TBTCl) and Goodman et al. (1988) for A. bahia (1,100 ng.L $\mathrm{L}^{-1}$ of TBT). Davidson et al. (1986) and Valkirs et al. (1987) also observed acute TBT toxicity within the range (300-420 ng. $\left.\mathrm{L}^{-1}\right)$ for mysid shrimp. Tributyltin compounds thus are highly toxic to adult brine shrimp. It can be speculated from these results that, TBT contamination, which can still reach concentrations of 200 ng. $\mathrm{L}^{-1}$ despite restrictive regulations (Michel et al. 2001; Osterberg et al. 2012), may be a potential threat to resident Artemia populations.

In addition, there was a report by Varó et al. (2015) stated that the potential role of an organophosphate pesticide, chlorpyrifos, in a congeneric mechanism of competition between the bisexual $A$. franciscana and $A$. parthenogenetica. They found evidence that both $A$. franciscana and $A$. parthenogenetica showed an elevated tolerance to high ranges of chlorpyrifos, but $A$. franciscana survived better and its fecundity was less affected by the exposure to the pesticide than that of $A$. parthenogenetica. A study by Rosser (2010) showed the effect of alcohol percentage on the development rate of A. salina nauplii and his found that alcohol does affect the development of brine shrimp in the group $0.025 \%$ alcohol having slowest development. Most of studies have focused on change morphological changes in nauplii stage, but in present study the toxicity of TBTCl was tested against $A$. salina in the adult stage male and female of brine shrimp, which undergo certain changes in morphological characteristics, as well as total length, head width, abdominal width, tail width during the 24 hours period. The one-way ANOVA employed indicated a substantial difference at $\mathrm{p}<0.01$ between the averages mean of total length, head width, abdomen width and tail width, with the different toxic concentration. However, the effect of the toxicity of TBTCl and it differences in sensitivity could be expected on marine crustacean species. It is obvious that TBTCl residues are constantly entering into marine water, which causes adverse effects to marine organisms.

Present study supports the use of brine shrimp assay as a simple and accurate to assess the marine aquatic toxicity profile of any toxicant, among others similar to that proposed by Vanhaecke et al. (1981) and Zulkifli et al. (2014). It also demonstrated that TBTCl alter the morphological structures of adult females and males of brine shrimp. Further experiments are warranted to study the effects of extensively used TBT against different marine aquatic organisms. Based on these findings there is a strong concern to use TBTCl. The results of the present study may add some information towards this direction, clarifying the higher magnitude of TBTCl toxicity.

\section{Conclusion}

Present study showed that $A$. salina females were more sensitive to TBTCl toxicity test when compared to male as the $\mathrm{LC}_{50}$ values for TBTCl are 94.72 ng. $\mathrm{L}^{-1}$ in female, and 146.99 ng. $\mathrm{L}^{-1}$ in male this indicated that $\mathrm{TBTCl}$ is toxic, proven that $\mathrm{TBTCl}$ is environmentally toxic substances. Limited studies have demonstrated significant morphologic differences occurrence and their toxicity on A. salina adult. However, the effect of toxicity of TBTCl and differences in sensitivity could be expected on marine species. As it was earlier stated, acute toxicity alone does not give enough information about the environmental impact of using such an antifouling agent. Further long-term toxicity studies and synergistic effects investigations would permit the complete evaluation of TBTCl as hazardous chemicals to aquatic organisms.

\section{Acknowledgement}

This study was jointly supported by the Fundamental Research Grant Scheme (FRGS) (Reference No. KPT.P.(S)400-7/2/294(65))from the Malaysia Ministry of Higher Education and the JSPS Core-to-Core Program.

\section{References}

[1] Abreu-Grobois FA (1987), A review of the genetics of Artemia. Artemia Research and Its Applications 1, 61-99.

[2] Abubakar A, Mustafa MB, Johari WLW, Zulkifli SZ \& Yusuff FBM (2016), Tributyltin (TBT) tolerance of indigenous and non-indigenous bacterial species. Water, Air, \& Soil Pollution 227, 1-8. https://doi.org/10.1007/s11270-016-2946-4

[3] Alzieu C (1998), Tributyltin: case study of a chronic contaminant in the coastal environment. Ocean \& Coastal Management 40, 23-36. https://doi.org/10.1016/S0964-5691(98)00036-2.

[4] Al-Rashdi A (2011), Improving the measurement of butyltin compounds in environmental samples. University of Southampton, Southampton, 190pp.

[5] Bartley DM \& Minchin D (1996), Precautionary approach to the introduction and transfer of aquatic species. FAO Fisheries Technical Paper, Rome, pp. 159-190.

[6] Bryan GW \& Gibbs PE (1991), Impact of low concentrations of tributyltin (TBT) on marine organisms: a review. In Metal ecotoxicology: concepts and applications (Newman MC \& McIntosh AW eds.), Lewis Publishers \& CRC Press, Boca Raton, pp. 323-361.

[7] Bustos-Obregon E \& Vargas A (2010), Chronic toxicity bioassay with populations of the crustacean Artemia salina exposed to the organophosphate diazinon. Biological Research 43, 357-362. https://doi.org/10.4067/s0716-97602010000300013.

[8] Champeau O \& Narbonne JF (2006), Effects of tributyltin and 17 $\beta$ estradiol on immune and lysosomal systems of the Asian clam Corbicula fluminea (M.). Environmental Toxicology and Pharmacology 21, 323-330. https://doi.org/10.1016/j.etap.2005.10.007.

[9] Cima F, Bragadin M \& Ballarin L (2008), Toxic effects of new antifouling compounds on tunicate haemocytes: I. Sea-Nine $211^{\mathrm{TM}}$ and chlorothalonil. Aquatic Toxicology 86, 299-312. https://doi.org/10.1016/j.aquatox.2007.11.010.

[10] Davidson B, Valkirs A \& Seligman PF (1986), Acute and chronic effects of tributyltin of the mysid Acanthomysis sculpta (Crustacea, Mysidacea). In OCEANS'86, pp. 1219-1225. https://doi.org/10.1109/OCEANS.1986.1160365.

[11] Fergusson L (2015), Three Bench-scale tests designed to destroy tributyltin (TBT) in marine sediments from north Queensland, Australia. Journal of Environmental \& Analytical Toxicology 5, 1-7.

[12] Goodman LR, Cripe GM, Moody PH \& Halsell DG (1988), Acute toxicity of malathion, tetrabromobisphenol-A, and tributyltin chloride to mysids (Mysidopsis bahia) of three ages. Bulletin of Environmental Contamination and Toxicology 41, 746-753. https://doi.org/10.1007/BF02021028.

[13] Hassanatabar F, Ouraji H, Esmaeili A \& Babaei SS (2013), Study of the activities of digestive enzymes, amylase and alkaline phosphatase, in Kutum Larvae, Rutilus frisii kutum fed Artemia nauplii. World Journal of Fish and Marine Sciences 5, 266-270.

[14] Ismail A, Ferdaus MY \& Syaizwan ZZ (2004), Imposex in Thais sp. along the Straits of Malacca. In Proceedings of the First Joint Seminar on Coastal Oceanography, pp. 189-196.

[15] Kanwar AS (2007), Brine shrimp (Artemia salina) - a marine animal for simple and rapid biological assays. Journal of Chinese Clinical Medicine 2, 236-240. 
[16] Kokkali V, Katramados I \& Newman JD (2011), Monitoring the effect of metal ions on the mobility of Artemia salina nauplii. Biosensors 1, 36-45. https://doi.org/10.3390/bios1020036.

[17] Michel P, Averty B, Andral B, Chiffoleau JF \& Galgani F (2001), Tributyltin along the coasts of Corsica (Western Mediterranean): a persistent problem. Marine Pollution Bulletin 42, 1128-1132. https://doi.org/10.1016/S0025-326X(01)00101-1.

[18] Mohamat-Yusuff F, Sien KW, Johari WLW, Ismail A, Zulkifli SZ \& Mustafa M (2014), Potential tributyl-tin (TBT) biodegradation agent in contaminated sediment. Malayan Nature Journal 66, 81-93.

[19] Mohamat-Yusuff F, Zulkifli SZ \& Ismail A (2011), Imposex study on Thais tuberosa from port and non-port areas along the west coast of Peninsular Malaysia. Journal of Tropical Marine Ecosystem 1(2), $1-9$.

[20] Mohamat-Yusuff F, Zulkifli SZ, Ismail A, Harino H, Yusoff MK \& Arai T (2010), Imposex in Thais gradata as a biomarker for TBT contamination on the southern coast of Peninsular Malaysia. Water, Air, \& Soil Pollution 211, 443-457. https://doi.org/10.1007/s11270009-0314-3.

[21] Mohamat-Yusuff F, Zulkifli SZ, Otake T, Harino H \& Ismail A (2014), Study on a new mechanism of sterilization in imposex affected females of tropical marine neogastropod, Thais sp. Journal of Environmental Biology 35, 995-1003.

[22] Nunes BS, Carvalho FD, Guilhermino LM \& Van Stappen G (2006), Use of the genus Artemia in ecotoxicity testing. Environmental Pollution 144, 453-462. https://doi.org/10.1016/i.envpol.2005.12.037.

[23] Ohji M, Takeuchi I, Takahashi S, Tanabe S \& Miyazaki N (2002) Differences in the acute toxicities of tributyltin between the Caprellidea and the Gammaridea (Crustacea: Amphipoda). Marine Pollution Bulletin 44, 16-24. https://doi.org/10.1016/S0025 326X(01)00146-1.

[24] Osterberg JS, Darnell KM, Blickley TM, Romano JA \& Rittschof D (2012), Acute toxicity and sub-lethal effects of common pesticides in post-larval and juvenile blue crabs, Callinectes sapidus. Journal of Experimental Marine Biology and Ecology 424, 5-14. https://doi.org/10.1016/j.jembe.2012.05.004

[25] Panagoula B, Panayiota M \& Iliopoulou-Georgudaki J (2002), Acute toxicity of TBT and Irgarol in Artemia salina. International Journal of Toxicology 21, 231-233. https://doi.org/10.1080/10915810290096360.

[26] Roozbehfar R, Jamali H \& Hematian R (2012), The potential of Russian sturgeon (Acipenser gueldenstaedtii) in exploitation of Artemia urmiana in comparison with Daphnia sp. and its mixture. World Applied Science Journal 20, 776-780.

[27] Rosser W (2010), The effect of alchohol percentage on the development of Artemia salina. Central Virginia Governor's School, Lynchburg.

[28] Sahandi J, Jafariyan H, Dehghan M, Adineh H \& Shohreh P (2012), Direct inoculation of Bacillus to rearing fish tanks effecton growth performance of two carp species fed with Artemia sp. World Applied Science Journal 20, 687-690.

[29] Shaala NMA, Zulkifli SZ, Ismail A, Azmai MNA \& MohamatYusuff F (2015a), Selected morphological changes in nauplii of brine shrimp (Artemia salina) after tributyltin chloride (TBTCl) exposure. World Applied Science Journal 33, 1334-1340.

[30] Shaala NMA, Zulkifli SZ, Ismail A, Azmai MNA \& MohamatYusuff F (2015b), Lethal concentration 50 (LC50) and effects of Diuron on morphology of brine shrimp Artemia salina (Branchiopoda: Anostraca) Nauplii. Procedia Environmental Sciences 30, 279-284. https://doi.org/10.1016/j.proenv.2015.10.050

[31] Sorgeloos P, Baeza-Mesa M, Bossuyt E, Bruggeman E, Dobbeleir J, Versichele D, Laviña E \& Bernardino A (1980), Culture of Artemia on rice bran: the conversion of a waste-product into highly nutritive animal protein. Aquaculture 21, 393-396. https://doi.org/10.1016/0044-8486(80)90075-7.

[32] Toi HT, Boeckx P, Sorgeloos P, Bossier P \& Van Stappen G (2013), Bacteria contribute to Artemia nutrition in algae-limited conditions: A laboratory $\quad$ study. Aquaculture 388, 1-7. https://doi.org/10.1016/j.aquaculture.2013.01.005.

[33] Valkirs AO, Davidson BM \& Seligman PF (1987), Sublethal growth effects and mortality to marine bivalves from long-term exposure to tributyltin. Chemosphere 16, 201-220. https://doi.org/10.1016/00456535(87)90124-X

[34] Vanhaecke P, Persoone G, Claus C \& Sorgeloos P (1981), Proposal for a short-term toxicity test with Artemia nauplii. Ecotoxicology and Environmental Safety 5, 382-387. https://doi.org/10.1016/01476513(81)90012-9.

[35] Varó I, Navarro JC, Amat F \& Guilhermino L (2002), Characterisation of cholinesterases and evaluation of the inhibitory potential of chlorpyrifos and dichlorvos to Artemia salina and Artemia parthenogenetica. Chemosphere 48, 563-569. https://doi.org/10.1016/S0045 6535(02)00075-9.

[36] Varó I, Redón S, Garcia-Roger EM, Amat F, Guinot D, Serrano R \& Navarro J (2015), Aquatic pollution may favor the success of the invasive species A. franciscana. Aquatic Toxicology 161, 208-220. https://doi.org/10.1016/j.aquatox.2015.02.008.

[37] Verslycke T, Poelmans S, De Wasch K, Vercauteren J, Devos C, Moens L, Sandra P, Brabander HFD \& Janssen CR (2003), Testosterone metabolism in the estuarine mysid Neomysis integer (Crustacea; Mysidacea) following tributyltin exposure. Environmental Toxicology and Chemistry 22, 2030-2036. https://doi.org/10.1002/etc.5620220910.

[38] Zulkifli SZ, Aziz FZA, Ajis SZM \& Ismail A (2014), Nauplii of brine shrimp (Artemia salina) as a potential toxicity testing organism for heavy metals contamination. In From Sources to Solution (Aris AZ Tengku Ismail TH, Harun R, Abdullah AM, Ishak MY, eds.), Springer, Singapore, pp. 233-237. https://doi.org/10.1007/978-9814560-70-2_43. 